\title{
NOTAS PARA VOLVER A VER LA FRONTERA
}

PEDRO SILLER

\section{RESUMEN}

T a noción de frontera ha variado a lo largo de la historia y en el caso del norte de México pasa desde referirse de maJnera amplia a un territorio intermedio, borroso y elástico en la época colonial, hasta fines del siglo XIX cuando se le define como una línea delgada y rígida, que separa dos estados-nación como "frontera." En este trabajo intentamos recorrer desde que se crea la frontera norte tal y como la conocemos hoy, hasta el final del periodo porfirista. El camino a seguir pasa por los conflictos frontera-centralismo para explicar la evolución de la primera, su concepción a fin de siglo y los problemas del Estado-nación de entonces para imponer su política e identidad a los habitantes fronterizos. En síntesis, como no puede haber frontera sin centro, no es posible entender la noción de frontera sin la de "centralización".

Palabras clave: Frontera, colonización, centralización, región, identidad, muro defensivo, violencia

\section{LA FRONTERA, HISTORIA DE UN CONCEPTO}

The history of the world is best observed from the frontier (Pierre Vilar)

A lo largo de la historia la palabra frontera ha conocido varias denominaciones, pues fue usada desde el siglo xiI en los documentos españoles y por los trabajos de los pensadores iusnatura- 
listas como Francisco de Vitoria y Francisco Suárez. Las primeras nociones se refieren a la parte frontal de los territorios, como el de España y el mundo árabe y después como la demarcación de la zona o confín hasta donde irradiaba el poder del monarca. ${ }^{1}$

Lo anterior se refiere también a la evolución de su significado, es decir, desde, de manera amplia, a un territorio intermedio, borroso y elástico, como fue el caso de la franja entre los territorios españoles en América y los Estados Unidos, hasta fines del siglo xIX cuando se define a la línea, ahora sí, delgada y rígida, que separa dos estados-nación como "frontera". Se pasa pues de la idea de frontera como espacio territorial al de "límite" como línea fija. Esto significa que ha existido una transformación de una forma a otra que va paralela a la creación del Estado-nación.

En México, la frontera norte, como región, ha estado presente en cada uno de los momentos críticos de la nación. Alcanzarla fue el frustrado propósito del padre de la patria, Miguel Hidalgo, quien trató de refugiarse en ella en julio de 1811 y en su intento fue apresado y fusilado en Chihuahua; después marcó la cicatriz mexicana de la guerra de 1846-48; fue el refugio de Benito Juárez y los hombres de la Refoma en 1865 frente a los amagos de los intervencionistas extranjeros; fue la zona que permitió a Porfirio Díaz conformar un ejército y entrar triunfante en 1876 a la ciudad de México para iniciar su presidencia, que duró hasta 1911, y finalmente, fue la franja en donde la Revolución Mexicana hizo su estallido inicial. Fue pues, un territorio relativamente autónomo desde donde se resolvían de una u otra forma los conflictos centrales.

En este trabajo intentamos recorrer particularmente desde 1848 a 1910, es decir, un periodo de 62 años desde que se crea la frontera norte tal y como la conocemos hoy con el Tratado de Guadalupe Hidalgo, hasta el final del periodo porfirista, cuando a nuestro juicio quedaron delineados los perfiles del Estado-nación mexicano.

Durante este periodo, el proceso de consolidación del Estadonación obligó a recurrir al centralismo como una forma de economizar esfuerzos para afirmar su presencia. Fue hasta el fin del siglo XIX, sobre todo gracias a los ferrocarriles, cuando el centro

\footnotetext{
1 Arriaga Rodríguez, 2013, 6.
} 
logró dominar a la mayor parte del territorio nacional incluyendo a los estados fronterizos y consolidó su dominio financiero sobre la población que habitaba la línea que limita con el exterior, todo esto con permanentes tensiones centro-periferia.

El camino seguido durante esta exposición pasa por los conflictos frontera-centralismo para explicar la evolución de la primera, su concepción a fin de siglo y los problemas del estadonación de entonces para imponer su política e identidad a los habitantes fronterizos. En síntesis, como no puede haber frontera sin centro, no es posible entender la noción de frontera sin la de "centralización”.

\section{LA FRONTERA COLONIAL}

La presencia del centro durante la colonización española se constituyó como una cadena de presidios para delimitar el territorio ocupado y el de los indígenas, que resistían la avanzada de los españoles, mestizos e indios propiedad de los encomenderos del centro y que eran llevados al norte para combatir a los insumisos. Así, la progresiva colonización del norte fue hecha por individuos que no tenían una identidad común y una vez establecidos conformaron asociaciones en defensa de su tierra y de sus familias frente al embate de los indios, lo que fue completamente diferente al centro-sur en donde la simbiosis con las poblaciones indígenas conformó una sociedad relativamente pacífica. ${ }^{2}$

Desde la época colonial, los informes sobre lo que hoy es el Norte mexicano fueron escandalosos. El ingeniero Nicolás de Lafora, comisionado por el rey de España a recorrer la frontera norte en el siglo xviII, escribió sobre unas inmensas tierras "mal registradas y peor descritas" ${ }^{3}$ en su Viaje a los presidios internos de la América septentrional y que fue producto de la expedición que realizara entre 1766 y 1768 a los puntos de avanzada más al norte del reino español, ahí relató al referirse a la nación apache y las diversas denominaciones que se le atribuían (gileños, xicarillas, pharaones, etcétera), la suma crueldad con que trataban

2 Rajchenberg, 2005, 2.

3 Meza, 2009, 3. 
a los vencidos, atenazándolos vivos y comiéndose la carne que les arrancan, flechándolos... habiendo llegado repetidas veces el caso en la Nueva Vizcaya, de abrir vivas las mujeres encintas, y sacándoles las criaturas, azotarlas con ellas, hasta hacerlas expirar. En otro punto de su extenso viaje, aseguró haber encontrado a una española esclavizada y que sus propietarios no quisieron saber de autoridades reales ni de dinero para liberarlas. ${ }^{4}$

Así, los primeros colonos del Norte de la llamada "región chichimeca" estuvieron marcados por las constantes amenazas de los indios rebeldes y a menudo se hacían comparaciones entre los que llamaban nobles y pacíficos indios del centro-sur y los salvajes e indómitos norteños.

Descartando la funcionalidad de los presidios, Lafora observó la importancia de las riberas del río Grande del Norte como una región clave para ejercer un control más efectivo para resolver los problemas de la frontera. Desde Santa Fe, donde comienza el Río, hasta su desembocadura en el golfo, sus márgenes permitían el establecimiento de pueblos, colonias y zonas agrícolas y ganaderas donde florecerían, como efectivamente sucedió durante el siglo XIX, "plantaciones de vinos, aguardiente, semillas, maderas, etc. y enviar al seno mejicano los frutos superfluos, las lanas y pieles, siendo este río navegable en canoas por toda esta distancia, lo que produciría unos efectos admirables, y una suma facilidad para hacer de él una barrera infranqueable para los indios que actualmente se introducen por este despoblado a destruir nuestras posesiones interiores". 5

\section{LOS INICIOS DEL MÉXICO INDEPENDIENTE Y LA ENTONCES NOCIÓN DE FRONTERA}

En 1819, los Estados Unidos y España firmaron un tratado de límites, el tratado Onís-Adams, en el que quedaron establecidos a grandes rasgos los dominios territoriales del norte novohispano que posteriormente heredaría la República Mexicana. ${ }^{6}$

\footnotetext{
4 Rajchenberg, 2005, 2.

5 Meza, 2009, 5.

6 Rajchenberg, 2005, 8.
} 
A la consumación de la independencia, la nueva República consideró a los puertos marítimos como su frontera, y las aduanas porteñas se conviertieron en su fuente principal de ingresos, prueba de ello es que los primeros decretos sirvieron para establecer los aranceles a las mercancías de comercio exterior que transitan por esa vía, por ejemplo, el Arancel general interino e instrucción para gobierno de las aduanas marítimas en el comercio libre del Imperio Mexicano de 1821. ${ }^{7}$ Por su parte, los Estados Unidos también consideraban al comercio exterior como sinónimo de comercio marítimo.

A lo largo de la primera mitad del siglo xix hubo una permanente penuria del gobierno federal mexicano que propició la autonomía de su región norteña, por lo que tuvieron que resolver solos sus problemas de organización política. A esto se sumó un recrudecimiento de las guerras indias, sobre todo a partir de 1831 con el desmantelamiento del ejército colonial, porque ni el reciente gobierno nacional ni el estatal, podían mantener a los indios en sus reservaciones, el racionamiento de víveres fue cortado, los pactos fueron rotos y además, coincidiendo con la separación de Texas en 1836, la guerra apache adquirió una notoria intensidad y la defensa de los norteños corrió por cuenta propia. Así, los colonos norteños hicieron todo lo posible por defenderse y mantener entre sí ese contrato de mutua protección no escrito y poco a poco perdieron la fe en las habilidades del gobierno central para defenderlos.

Estas guerras configuraron para los norteños un estatus especial, y quienes participaban fueron vistos con admiración y respeto; por ejemplo, algunos de ellos, aunque de origen humilde, al destacar en la guerra se les facilitaba contraer matrimonio con hijas de ricos rancheros. La organización de los combatientes estaba basada en el carisma personal que posteriormente era ratificado por la organización estatal en forma de grado militar y al interior, el grupo o "la partida" se caracterizaba por el igualitarismo; por ejemplo, se mencionaba que "como todos los hombres de espíritu" eran "extremadamente celosos" de su honor, los jefes

7 México, Imprenta de don Celerino de la Torre, 1821. 
estaban obligados a dirigirse al resto de los hombres como iguales en las conversaciones. Como menciona Alonso, "la camaradería de hombres de un grupo de iguales frente a la muerte, prevalecía frente a la desigualdad formal impuesta por la jerarquía militar". 8

\section{LA FRONTERA DESDE 1848}

La localización de las aduanas en la frontera norte fue un indicador de su importancia. Hasta la década de los ochenta, apenas cubrían la mitad de la línea fronteriza, pues iban desde Bagdad y Matamoros hasta Paso del Norte, pasando por Camargo, Mier, Piedras Negras y Monterrey; ${ }^{9}$ es decir, las márgenes del Bravo como lo había previsto Lafora. A partir de Paso del Norte hacia el Pacífico fue lo que se llama una frontera "hueca" es decir, incapaz de delimitarse debido a la falta de una frontera natural (el Río Bravo) y las similitudes territoriales y culturales de uno y otro lado.

En términos de identidad, para los residentes en la zona fronteriza del Río Bravo la partición del territorio en 1836 con la independencia de Texas fue algo más simbólico que real, pero la de 1846 fue, ahora sí, más que una simple línea en medio del desierto. La nueva frontera claramente separó a dos naciones con diferente nivel de desarrollo. Años después, los cartógrafos y miembros de las comisiones de límites elaboraron mapas de la región, establecieron guarniciones militares, aduanas, oficinas de correos, y se dieron cuenta de que no se trataba simplemente de una marca sino de una separación brutal entre unas poblaciones y otras quienes tradicionalmente habían estado unidas, sin dejar de lado que Texas había logrado su independencia desde 1836. Desde uno y otro lado de los centros dirigentes, se habían tomado decisiones que afectaron sus vidas de una manera decisiva. ${ }^{10}$ Pero era evidente que no les reconocían su importancia, en 1851 la legislatura del estado de Chihuahua se quejaba de que:

8 Alonso,1995, 33.

9 Rajchenberg, 2005, 10.

10 Arriaga, 2005, 22. 
En México se tratan los negocios del estado de Chihuahua con tanta indiferencia y tanto desprecio, que aun sin abrir, han visto algunas personas fidedignas pliegos de este Estado, en algunos ministerios del Jefe Supremo de la Nación, por manera que acaso ni serían leídas las quejas por amargas y cáusticas que fueran, ni probablemente aun cuando tuvieran veneno las cubiertas no se dañarían con él, porque acaso ni lo abrirían para imponerse de su contenido, con solo ver que es dirigido por el remoto e infeliz estado de Chihuahua [...] Finalmente, que aunque con sentimiento, no puede menos de recordar [la legislatura], porque es verdad, que el gobierno general no ha visto, ni tratado de otra manera al estado de Chihuahua, que como a entenado, hablando en frase común, pero inteligible para todos. ${ }^{11}$

Después de la división en 1846, otro acontecimiento muy importante enmarcó y condicionó con firmeza el funcionamiento de la línea fronteriza diseñada por el río Bravo: la guerra de secesión en los Estados Unidos. Colindante con la fracción sureña, los estados de Tamaulipas, Nuevo León, Coahuila y Chihuahua fueron los que sintieron, para bien o para mal, los impactos de la guerra. El contrabando en uno y otro sentido fue la fuente de la riqueza para muchos comerciantes y políticos mexicanos: los Madero, los Carranza, los Terrazas y muchas otras familias, lograron amasar importantes fortunas ya fuera con el contrabando del algodón hacia México o con el de armas y víveres para el ejército sureño. Así que los conflictos civiles e internacionales sacudieron ambas sociedades en momentos en que se definían como estado-nación. ${ }^{12}$

¿Quiénes estaban implicados en el contrabando? Todos los que estaban de una manera u otra en una actividad mercantil en la frontera: no existía una casa comercial que no tratara de sacar un provecho económico burlando las leyes vigentes y además, toda la red local: guardias fiscales, arrieros, transportistas, comandantes de plaza, recaudadores de impuestos, jefes políticos, gobernadores, etcétera. ${ }^{13}$

11 Herrera Pérez, 2004, 150.

12 Cerutti, 1990, 217.

13 Benavides Hinojosa, el general Bernardo Reyes, 140. 
Prácticamente hasta la llegada del ferrocarril en 1884 a Paso del Norte, los estados nacionales fueron incapaces de mantener el control sobre la frontera, pues como puede advertirse, excedía a sus posibilidades económicas. El grado de inseguridad fue tal que en un documento se dice:

Partidas de americanos, de tejanos, de mexicanos y de indios libres dieron fin en pocos años a la riqueza pecuaria de aquel territorio: con poca población este, sin que sobre él se ejerciera la acción constante de las autoridades mexicanas o tejanas, no solo se perdió la riqueza, sino que se produjo una enorme inmoralidad. La primera inmigración llegada a aquella parte de Texas, no corrigió esas condiciones, y por el contrario, las agravó, porque los inmigrantes no se distinguían por la rectitud de su carácter. Allí encontraron refugio los criminales prófugos de México por sus delitos, [...] la sed de riqueza era una tendencia de tal manera desarrollada, que para adquirirla, todos los medios parecían lícitos. ${ }^{14}$

Para los colonos fronterizos atrapados enmedio de la violencia, el gobierno central nunca apareció en su auxilio por lo que perdieron la fe en que pudiera hacerse cargo de su protección, especialmente durante el gobierno de Santa Anna cuando vieron a los militares de ejército mexicano como "lobos" que se apropiaban de sus caballos, ganado y peor, obligaban a sus jóvenes a incorporarse al ejército. ${ }^{15}$

A pesar de la bonanza norteña por la guerra de secesión, la franja fronteriza no estaba integrada al mercado interno mexicano. A mediados de siglo, el transporte de mercancías con recuas de mulas se realizaba a razón de cinco o seis leguas diarias, lo que significaba que para llegar desde la capital hasta la frontera norte se consumían alrededor de 120 días. Además de esto, la cantidad de alcabalas que tenían que pagar los comerciantes hacía imposible el intercambio de mercancías norte-centro y viceversa.

La región cobró una enorme autonomía después de la guerra del 48 con el establecimiento de la zona libre en 1858, es decir:

14 Comision pesquisidora, 1873, 7.

15 Mora, 2001, 41. 
"una franja territorial en la que se permitía la introducción de toda clase de mercancías extranjeras, para consumo de sus habitantes, sin necesidad de cubrir el pago de los derechos aduanales aunque sí algunos pequeños impuestos locales". ${ }^{16}$ Esto para los márgenes del Bravo, o sea, se extendió de Matamoros, Tamaulipas a El Paso, Texas.

La franja pronto se convirtió en un espacio de contrabando, tanto hacia los Estados Unidos, como para el resto del norte de México debido a la facilidad de importar productos de Europa y trasladarlos en medio de un espacio fuera de toda ley aduanera e introducirlos a uno u otro país a partir de casi cualquier punto. Los comerciantes fueron los mejores indicadores de esta ruta: La Casa Blanca, Moye, Krakauer, etcétera. Así, los estados norteños comenzaron a incorporarse a la economía mundial y el Norte continuó con su característica distintiva de independencia. Era una zona de toque entre dos países pero era una economía aparte.

Es factible afirmar que, durante la guerra civil norteamericana entre 1862 y 1865, el Río Bravo, lejos de configurar una barrera disociadora, fue la matriz de una historia económica común. Aunque separaba dos países en términos jurídicos y políticos, unía con generosidad ámbitos regionales importantes de esos estados nacionales, al menos en el plano del movimiento mercantil. Al mismo tiempo, la guerra de Reforma y la posterior intervención francesa en México impidieron controlar el norte desde el centro.

Durante la guerra de Reforma, el ejército del Norte encabezado por Vidaurri llegó a tener cinco mil hombres combatiendo, todos ellos "bien armados, con grandes reservas de munición y bien uniformados. Todo lo que llevaban era nuevo, las armas, los implementos de campaña, las frazadas, etc.". Comprado todo en los Estados Unidos, ¿de dónde salió el dinero? De una permanente economía de guerra y del contrabando. ${ }^{17}$

Después, el ejército más importante con el que México pudo contar para hacer frente a los invasores, fue precisamente el formado en el Norte, en la zona fronteriza de Nuevo León y Chihuahua con Texas con personajes como Ignacio Zaragoza, Mariano

16 Herrera Pérez, 2004, 16.

17 Mora, 2001, 10.

Chinuahua Hoy 2016 
Escobedo, Gerónimo Treviño, Francisco Naranjo, Manuel González y muchos otros, todos ellos veteranos de las luchas contra los indígenas norteños, contra los norteamericanos en 1846 y contra los conservadores en la guerra de Reforma (1857-59). En estas guerras se conocieron todos ellos con Porfirio Díaz, lo que permitió a este último una alianza que duraría durante el resto del siglo XIX.

Fue por la lealtad de los norteños durante estas guerras, que frente a la caída de la ciudad de México en 1863, Benito Juárez emprendió su viaje al norte en busca de su aliado el gobernador del estado de Nuevo León-Coahuila Santiago Vidaurri, para establecer su gobierno. Juárez esperaba que Vidaurri compartiera con él los productos de las aduanas fronterizas y que sirvieran para la compra de armas y organizar la contraofensiva, pero el neoleonés se negó aduciendo intereses regionales y reprochándole a Juárez el nulo apoyo del centro durante los últimos años.

Después de algunos enfrentamientos inclusive armados Juárez decidió entonces acudir a Chihuahua en busca del apoyo para proseguir su lucha y lo encontró, aunque con ciertas reticencias por las mismas razones de Vidaurri, con el gobernador Luis Terrazas.

Finalmente, con el apoyo de los norteños dirigidos por el general Escobedo, finalmente cercaron a Maximiliano en Querétaro y lo fusilaron en julio de 1867. Así, Juárez logró entrar victorioso a la Ciudad de México y restaurar la República.

\section{EL PORFIRISMO Y LA FRONTERA}

El 27 de septiembre de 1871, el compañero de armas de Díaz desde los tiempos de las luchas contra los conservadores, Jerónimo Treviño, entonces de 36 años originario de Cadereyta, Nuevo León, se levantó en armas contra el régimen juarista en Monterrey. Tenía un importante ascendiente local, se inició como militar en la guerra de Reforma en 1858, combatió en Oaxaca y durante la intervención extranjera participó en muchas batallas incluida la de Puebla en mayo de 1862; después regresó a combatir en el Norte a las órdenes del general Mariano Escobedo quien lo ascendió a general de brigada y se mantuvo siempre leal a Juárez ante las defecciones de caudillos locales como Vidaurri; en 1867 participó 
en la toma de la ciudad de Querétaro, último bastión del imperio de Maximiliano y fue nombrado gobernador del estado de Nuevo León en diciembre de ese año.

Como se acostumbraba, el hombre fuerte de la región era el que controlaba las aduanas y buena parte de la zona libre. Pero desde 1870, los norteamericanos insistían en la desaparición de esta zona porque argumentaban que desde ahí se generaba muchísimo contrabando hacia su interior, así que México se encontraba en una disyuntiva: terminar con la zona libre implicaba enfrentarse con los caudillos norteños que habían hecho de esta y de las aduanas correspondientes, un modus vivendi muy redituable que ahora estaba en peligro frente a un Juárez que reclamaba las aduanas para fortalecer a una nación necesitada de recursos para subsistir.

Así que el gobernador de Nuevo León, Geronimo Treviño y ahora el general Francisco Naranjo, compañero del primero en muchas batallas, invitaron al general más popular a encabezar la rebelión, a Porfirio Díaz. El Plan de La Noria fue firmado el 8 de octubre de 1871, es decir, después de que los fronterizos estaban ya levantados en armas. Ante el fracaso de los levantiscos, Díaz se vio obligado a huir hasta la muerte de Juárez y el ascenso de Sebastián Lerdo de Tejada.

El 24 de julio de 1872 Lerdo decretó la amnistía a la que se acogieron todos los generales aún con vida, incluyendo a Treviño, Naranjo, Guerra y en una hacienda chihuahuense cerca de Ciudad Camargo, Díaz aceptó los términos finales de la lucha a manos del juarista Luis Terrazas. Al año siguiente, Lerdo inició el rescate fiscal de la frontera norte, casi la derogación de la zona libre y en la primavera de 1876 estalló el brote rebelde fronterizo que se unió a la de Tuxtepec. ${ }^{18}$

Y es que Díaz nuevamente lanzó un plan insurgente, el Plan de Tuxtepec, en protesta contra la reelección de Lerdo de Tejada. Lo acompañaron nuevamente en Nuevo León y Tamaulipas sus antiguos camaradas que deseaban mantener sus privilegios de la zona libre, otra vez encabezados por Treviño y Naranjo. Prueba de

18 Herrera Pérez, 2004, 167-169.

Chinuahua Hoy 2016 
ello es que la primera acción de Díaz al tomar la ciudad fronteriza de Matamoros fue derogar toda la legislación de Lerdo sobre aduanas y reinstalar absolutamente la ley de 1856 sobre la zona libre..$^{19}$ Los fronterizos volvían a ser decisivos en la realización de las ambiciones de quienes deseaban gobernar desde el centro.

Además encontró aliados en esta nueva rebelión entre una incipiente clase media urbana, artesanos empobrecidos por las guerras, los cuadros medios del ejército, los antiguos aliados de Juárez, los nuevos lectores de libros y periódicos, a los católicos en busca de una reconciliación con el Estado y los inversionistas extranjeros entre ellos los empresarios ferrocarrileros a quienes Lerdo había desdeñado y pregonado que entre los Estados Unidos y México lo mejor era el desierto. Incluso el presidente de la Suprema Corte de Justicia, José María Iglesias, se había rebelado alegando la ilegalidad de la reelección por lo que le correspondía a él la presidencia. El 1. ${ }^{\circ}$ de octubre Iglesias huyó de la ciudad rumbo a Guanajuato donde intentó sin éxito formar un ejército y optó por el exilio.

De Matamoros, el caudillo se retiró para tomar Monterrey que estaba defendido por el general Mariano Escobedo pero fue sorprendido el 20 de mayo en Icamole, Nuevo León, donde fue derrotado y se dice que lloró amargamente y fue rescatado por Manuel González. A él le dejó la campaña del norte pues se embarcó en Texas para volver al sur, a Veracruz y de ahí a Oaxaca donde reunió a un pequeño ejército y reinició la lucha. Luego se dirigió a la Ciudad de México y en Texcoac el 16 de noviembre de 1876 se enfrentaron 3 mil hombres leales a Lerdo de Tejada y 5 mil rebeldes. La batalla fue decisiva porque Manuel González había recorrido con mil hombres todo el camino entre Matamoros y Puebla, casi dos mil kilómetros a caballo para ayudar a su compadre en esta batalla crucial. Nuevamente herido, sangrando del muñón del brazo derecho y de una pierna, arrojó a sus tropas al embate final que ganó completamente.

Después de un proceso difícil, el gobierno norteamericano reconoció como legítimo al de Díaz y para ello la consideración de

19 Ibid. 
la pacificación de la frontera norte y el reconocimiento de los daños en la franja fronteriza durante las pasadas guerras fue un punto nodal aunque quedaba pendiente lo de la zona libre.

El primer período de Díaz estaba por terminar y a petición de Díaz, a partir del 15 de noviembre comenzaron a reunirse gobernadores y caudillos regionales para lograr un acuerdo sobre los términos de las elecciones, los candidatos fueron Justo Benítez, amigo de Díaz desde los tiempos de Oaxaca y Manuel González. A medida que se desenvolvían las reuniones fue evidente el apoyo de los fronterizos al tamaulipeco González, sobre todo de los generales Jerónimo Treviño y Francisco Naranjo por lo que este resultó ganador. Todos participaron oficialmente y aceptaron el resultado final, ninguno se levantó en armas y González fue declarado Presidente Constitucional el 1. ${ }^{\circ}$ de diciembre de ese año, lo que fue un acontecimiento sorprendente ya que desde el inicio de la Independencia no se había logrado una sola transmisión pacífica del poder, ni hubiera sido posible sin los fronterizos.

Por esos días, llegaba el primer tren a El Paso, Texas, y los directivos de los ferrocarriles dirigían insistentemente sus miradas hacia el sur. Así que cuando el general Ulysses S. Grant, representante de los capitalistas estadounidenses deseosos de invertir en México, desembarcó en Veracruz en febrero de 1880 para permanecer casi un mes, encontró un país en calma y con visos de respeto a las inversiones extranjeras. Él tenía ideas muy claras sobre el futuro de ambos países:

No tengo duda de que con la construcción de ferrocarriles podríamos adquirir de México esos productos [azúcar, café, tabaco] que, en vez de tenerlos de países antidemocráticos, esclavistas y de excesivos derechos aduanales, los tendríamos de un país republicano, cuyos derechos de exportación son menores. Y ¿a qué precio? Ya no al de nuestro dinero, sino al de nuestros productos [maquinaria, herramientas, artefactos] que remitiremos a cambio de sus frutos. ${ }^{20}$

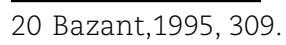


Por su parte, México, con la construcción del ferrocarril buscaba dos grandes objetivos. Primero, permitiría incrementar el comercio interior y exterior, y por ende, las actividades productivas; y segundo, quizá más importante que lo anterior, sería como una argamasa que uniría al territorio nacional, un eficaz vehículo para centralizar las decisiones y consolidar al gobierno federal como dirigente en la política económica al romper las murallas de los regionalismos y finalmente conquistar el norte. Tal y como escribió Friedrich List en el caso de Alemania (1841), los ferrocarriles eran "un tónico para el espíritu nacional" y "un ceñido cinturón en torno a los lomos de la nación”. Esto y la creación de un sistema nacional de impuestos daría como resultado la unificación de México.

El 30 de marzo de 1884 llegó a la frontera norte el primer tren desde la Ciudad de México. Antes de la construcción del ferrocarril, a las carretas les tomaba dos días desde la Ciudad de México a Querétaro, tres días a Irapuato, cuatro días a León, cinco días a Aguascalientes, seis días a Zacatecas, diez días a Chihuahua y once días a El Paso, con el ferrocarril se redujo a 8, 10, 12, 17, 21, 47 y 59 horas, respectivamente. La tarifa por persona se calculaba por kilómetro a 3, 2 y 1 centavo ya fuera en primera, segunda o tercera clase. Solo los de primera clase tenían derecho a una cama, que en el caso del viaje México-Paso del Norte, costaba nueve pesos y para redondear, un dos por ciento de impuesto, finalmente el costo era de alrededor de ochenta pesos el viaje sencillo. Esto era más o menos tres meses de salario de un trabajador norteño. La cantidad de viajeros en el Ferrocarril Central, 514 mil el primer año, nos hace pensar que era relativamente asequible.

El 21 de marzo de 1884, la oficina de correos aseguraba que mediante el Ferrocarril Central, una carta depositada en la oficina de correos en la Ciudad de México tardaría siete días en llegar a Nueva York, con un costo de seis centavos. Como resultado del aumento en la relación comercial en la frontera norte, el 10 de septiembre de 1889 se inauguró el entonces moderno edificio de la Aduana de Ciudad Juárez, símbolo de la dominación del centro sobre la frontera, que sería la sede de la entrevista Díaz-Taft diez años después. 
Pero la modernización tenía un precio, pues había que pagar las subvenciones a los ferrocarriles. Al principio fue cubierto con más deuda pública, luego con la venta de las acciones del gobierno sobre el ferrocarril México-Veracruz y también continuó con una práctica establecida desde los tiempos de la lucha contra la intervención extranjera: la venta de terrenos propiedad de la nación y por supuesto, la hipoteca sobre las aduanas. El ferrocarril utilizó al incipiente Estado nacional para expandirse y a su vez, este lo necesitaba para extender su dominio al interior del territorio. En cada estación construida descendían del tren sus representantes: el cobrador de impuestos, el recién nombrado gobernador o jefe político, el militar, el sacerdote, el encargado de los deslindes de tierra y el contingente de Rurales, entre otros.

En 1876, cuando se inicia el régimen porfirista, los ingresos por concepto de comercio exterior representaban el $66 \%$ del total de los ingresos federales y el impuesto del timbre -comercio interior-ascendía al $11 \%$, el resto era un $23 \%$ muy diverso. Como puede verse, existía una considerable dependencia de las aduanas, incluso hasta 1910 cuando a pesar del retiro de las alcabalas convertidas ya en impuestos federales, las aduanas fronterizas representaron el $44 \%$ de los ingresos. ${ }^{21}$

\section{LA REBELIÓN DE CATARINO GARZA EN 1892}

Pero la zona aledaña al río Bravo en ambas direcciones, aún después de la llegada de los ferrocarriles continuaba con los conflictos heredados desde el 48. La región de Tamaulipas fue una muestra del tipo de conflictos posteriores a la colonización de los "anglos" en Texas. La historia de Catarino Garza, nacido en Matamoros en 1859 fue la de miles de personas de origen mexicano que vivían en los terrenos de los que ahora los "anglos" insistían en expulsarlos. Periodista, encabezó las protestas por las arbitrariedades contra los mexicanos y la pasividad del gobierno de Díaz, así que entró a México con una regular fuerza armada a mediados de 1891 y en diciembre, los estadounidenses decidieron com-

21 Nuño, 2008, 13.

Chinuahua Hoy 2016 
batirlo en cuanto pasara a su territorio. El militar encargado de la operación escribió que la gente de la región simpatizaba abiertamente con él, por lo que era difícil localizarlo a pesar de que para perseguirlo, tenía mil 43 soldados, 186 oficiales y 63 comandantes. Entre los patrocinadores de Garza hubo todo tipo de personas, desde los mexicanos pequeños propietarios, hasta comerciantes y grandes empresarios, pero los más firmes simpatizantes fueron los jornaleros agrícolas y los vaqueros mexicanos, en palabras de otro militar estadounidense: "varios miles de ignorantes e irresponsables... muchos de ellos desesperados".

El movimiento de Catarino Garza paulatinamente decayó, pues fue víctima de la presión entre la fuerza porfirista, dirigida por el general Bernardo Reyes y la estadounidense. Dos años después, Garza escapó a Costa Rica desde donde colaboró con algunas rebeliones centroamericanas. En 1896 se encontraba junto con un grupo de rebeldes en Panamá, entonces una provincia colombiana, cuando desembarcó un destacamento de "marines" en la localidad de Boca del Toro y se inició el combate en el que murió el rebelde mexicano. Después se volvió una leyenda. Años después un cónsul mexicano en La Habana afirmó que estaba vivo y peleando con los patriotas cubanos; otro lo ubicaba al mismo tiempo en la lucha antidictatorial de Ecuador y así en adelante. ${ }^{22}$

Unos meses después de iniciada la rebelión de Garza, en la sierra de Chihuahua los habitantes del poblado de Tomóchic iniciaron lo que desencadenaría una de las mayores represiones contra un pueblo durante el porfirismo. La rebelión tuvo varios motivos, los abusos de los jefes municipales, el robo de unas imágenes religiosas por parte de un guardaespaldas del gobernador Lauro Carrillo para agradar a la esposa de este; un conflicto por el uso de la sede de la iglesia católica por los seguidores de Teresa Urrea "La santa de Cabora" y otros, pero no existe documentación que permita sugerir que hubo un conflicto de tierras, lo que sí es evidente es que hubo un desprecio a las autoridades federales (y al clero) cuando indignados por sucesivos agravios y bajo el liderazgo de Cruz Chávez prefirieron irse a visitar una imagen re-

22 Young, 1996, 254. 
ligiosa que asistir a una vana jornada electoral. El comunicado de Juan Ignacio Chávez, autoridad de Tomóchic, es muy expresivo y representativo de las ideas de los fronterizos:

... pongo en conocimiento de usted que la mayor parte de los vecinos de este pueblo, todos reunidos y armados se me han presentado manifestándome que desde hoy no debe contar como autoridad con la obediencia de ninguno de ellos, porque tienen el propósito de ser independientes de las leyes civiles y por tal razón no prestan obediencia a ninguna autoridad...23

Naturalmente, fueron brutalmente reprimidos por el ejército transportado en ferrocarril, pues de otra manera no hubiera sido posible. Teresa Urrea y algunos de sus seguidores más cercanos como Lauro Aguirre se exilaron primero a Sonora y luego a El Paso, Texas, donde mantuvieron su propaganda antiporfirista y denunciaron continuamente las atrocidades del régimen en Tomóchic.

Mientras tanto, en el centro se impulsaba con toda fuerza la idea de la necesidad del centralismo porque, como escribiera el ideólogo del porfirismo, Justo Sierra:

[Era] el responsable ante el mundo, a quien íbamos a pedir los elementos activos de nuestra transformación económica, del orden, de la paz, de la justicia, es decir, de la solvencia de nuestro erario, del poder del gobierno en todos los ámbitos del país, del respeto al Derecho, de todo cuanto fuese indicio de organización y respeto. ${ }^{24}$ Lo que además es una buena definición de lo que entendía por Estado y centralizarlo equivalía a una economía de esfuerzo para consolidarlo: su fortalecimiento iba a la par de la centralización y de los símbolos que la justificaban, es decir, del marco cultural que se necesita para gobernar y con esto los liberales hicieron del Estado su mejor arma.

Uno de estos símbolos fue el monumento a Cuauhtémoc en la Ciudad de Mexico iniciado por el entonces ministro de Fomento Vicente Riva Palacio en el cruce las avenidas Paseo de la Reforma

23 Osorio, 1995, 108.

24 Sierra, 1991, 362. 
e Insurgentes y que finalmente se inauguró el 21 de agosto de 1887, exactamente dos meses antes de que se reformara el artículo 78 para permitir una sola reelección inmediata del presidente. En el discurso inaugural se mencionó que el indígena Cuauhtémoc había defendido heroicamente "a la nacionalidad mexicana" y el monumento estaba construido de manera tal que significaba una pirámide de Teotihuacán con motivos zapotecos, mixtecos, mayas, toltecas y por supuesto aztecas, entre otros. Sin embargo, el personaje está vestido con una túnica como si fuera Sócrates, esta identidad, utilizada también en el neoclasicismo francés, fue muy común en México y se puede ver en la pintura El descubrimiento del pulque, de José Obregón (1869) o en el lienzo El senado de Tlaxcala de Rodrigo Gutiérrez (1875).

La idea de Cuauhtémoc como representante de la "nacionalidad" se deriva que si él (Cuauhtémoc) era el representante de una "nación" y su capital era Tenochtitlán, es obvio que los tributos a la nación azteca deberían continuarse ahora en forma de impuestos a la nación mexicana, y si el representante de la nación azteca vivía y mandaba desde Tenochtitlán no debería extrañar que el actual dirigente viva y mande desde la Ciudad de México. El centro del país, y en especial la ciudad de México, se constituía pues en el epicentro de la nacionalidad.

La herencia de esta tardía y trunca incorporación del Norte y en especial de los territorios fronterizos, se manifiesta hasta hoy: los símbolos nacionales -las pirámides, el charro, los aztecas, etcétera, no asumen prácticamente ningún elemento físico o cultural del norte. ${ }^{25}$

El patriotismo pues, fue un producto intelectual urbano que funcionó como un instrumento de conquista hacia las fronteras, muchas veces con tintes de explotación casi colonial. Tanto esta simbología como los libros de historia para niños estaban plagadas de imágenes de los pobladores del México prehispánico o de personajes del centro-sur (Cuauhtémoc, Hidalgo, Juárez, etcétera) con lo que se justificaba el centralismo.

25 Rajchenberg, 2005, 3. 
Así pues, las fronteras como procesos tienen tres dimensiones. Primero, son instrumentos de la política federal porque los gobiernos intentan modificar, para su propio beneficio, el lugar y las funciones de las fronteras. Segundo, las políticas impuestas por el centro están restringidas por la capacidad de control de facto sobre las zonas fronterizas; el reclamo de que el Estado es la única fuente legítima de violencia y de control se ve siempre cuestionado en las fronteras con el tráfico de personas, mercancías e información. Por tanto, es allí donde el centralismo mide su verdadera capacidad de poder y en una tercera dimensión, la frontera es también una marca de identidad, es decir ser "fronterizo" se convirtió desde mediados del siglo XIX en una forma de ser. ${ }^{26}$

\section{LAS DISPOSICIONES JURÍDICAS SOBRE LA FRONTERA: RESGUARDOS ADUANALES, ALCABALAS, ZONA LIBRE}

En 1896, en gran medida con el apoyo de los ferrocarriles, se logró finalmente eliminar las alcabalas, es decir, los cobros en las aduanas interiores y convertir estos impuestos regionales en impuestos federales con lo que se garantizaba una mayor recaudación y por tanto garantías para pagar la deuda pública extranjera. Esto se logró mediante negociaciones directamente con los gobernadores y los hombres fuertes de cada región. De todos los procedimientos de fortalecimiento del estado-nación ninguno tan importante para la desaparición de la balcanización económica. Pablo Macedo escribió:

Nuestra unidad política se constituyó a la restauración de la república en 1867, nuestra unidad económica se consumó el 1 de julio de 1896, al quedar bien, perdurablemente establecido, por el derrumbe de las barreras levantadas por nosotros mismos, que nuestros intereses son unos solos desde los Estados Unidos hasta Guatemala y desde el atlántico hasta el pacifico. ${ }^{27}$

26 Parte de esta argumentación en Anderson, 1996, 2.

27 Macedo, 1905, 63-64. 
Pero esto no fue posible en toda la República al mismo tiempo, en el norte no estallaron grandes protestas y generalmente fueron bien aceptadas por su interés en agilizar el comercio pero en algunas regiones como Oaxaca y Tabasco, sin ferrocarriles casi, la reacción fue tan fuerte que los levantamientos armados obligaron a Díaz a retroceder dejando sin efecto la ley, lo que sobrevivió hasta bien entrado el siglo xx. De hecho, el regionalismo era la verdadera base de la unidad nacional, por lo que uno de los mayores problemas era el de subordinar este regionalismo al interés nacional mediante el centralismo.

Una más de las medidas importantes como unificadoras de la economía nacional fue que a partir del 16 de septiembre de 1896 se hizo obligatorio el uso del sistema métrico decimal y aunque su aplicación fue lenta, el hecho de la unificación fue, como el de las alcabalas, muy significativo. En lugar de las tradicionales medidas como la vara (838 milímetros), el cuartillo (456 milésimos de litro), cuartillo de aceite (506 milésimos de litro) se usaría el metro y el litro. Además, era obligatorio que el café y el azúcar vendidos desde tiempo inmemorial por libras, onzas y arrobas, pasaran a hacerse en kilos con la siguiente equivalencia: una libra $=460$ gramos; una onza= 29 gramos; una arroba= 11 kilos y medio. La dificultad de conversión produjo un aumento real en los precios porque los comerciantes, al realizar la conversión que era imposible hacerla exactamente, preferían siempre equivocarse a favor suyo y no del cliente, a quien le daban menos por el mismo precio, por lo que estos preferían comprar donde se expedía con las medidas antiguas. Lo que sí fue importante es que la unificación de medidas permitió cobrar impuestos de manera uniforme en todo el país.

El otro enorme esfuerzo fue para extender el uso del registro civil a partir de 1890, algunos estados adoptaron la gratuidad en el trámite, la obligatoriedad para inscribirlos en las escuelas y la multa a los que no registraran a sus hijos. Si bien había quedado establecido con las Leyes de Reforma en 1859, lo cierto era que los jueces aún se enfrentaban a una férrea resistencia entre la población, excepto la expedición de las actas de defunción pues 
eran necesarias para el uso del panteón municipal. Esta resistencia deformaba cualquier proyección estadística.

Al mismo tiempo se insistía en legislar sobre la criminalidad y la administración de justicia, se inauguró en la capital la cárcel de Belem en 1900, con el "científico" Miguel Macedo como primer director, lo que refiere la importancia del proyecto; esto en medio de la fiebre reglamentadora como una característica de la lucha del progreso hacia la modernidad.

Al final de la época porfirista se reglamenta sobre todo lo existente, incluso sobre el espacio doméstico pues había que erradicar el mal hábito de la suciedad. Dos disposiciones legislativas, de 1889 y de 1892, establecieron que: "no debía haber fuertes corrientes de aire dentro de la casa; las habitaciones debían ventilarse unas tres o cuatro horas después de haber salido el sol esperando que la niebla de la mañana ya se hubiera disipado; se pedía tener las casas bien aseadas; no se debía tener amontonado el estiércol, los desperdicios de la cocina u otras materias que entraran en putrefacción y; evitar vivieran demasiadas personas en una misma habitación, pues se sabía que la aglomeración de muchas gentes en habitaciones bajas, frías y húmedas favorecía al desarrollo del cólera.

El Estado cumplía así su papel de uniformador, racionalizador, administrador y calculador que necesita la sociedad capitalista. Además de creador de leyes que permitan a la sociedad funcionar como si aquellas fueran uno de sus artefactos.

Así pues, el centralismo se entiende no solamente a las decisiones tomadas en la ciudad de México, sino también la existencia de un aparato que concentra el poder y emite desde ahí un discurso "nacional". Construir el centro significó:

el lugar privilegiado de un territorio donde se reúnen los recursos administrativos, económicos, militares y culturales; alberga los establecimientos de deliberación, negociación y decisión; la gente se reúne para realizar los ritos de afirmación de la identidad; es el lugar donde se encuentran los monumentos que simbolizan esta identidad; a su vez concentra a la mayor parte de la población activa en el manejo y difusión de las instrucciones y de informaciones a través de 
grandes espacios... un centro normalmente controla la mayoría de las transacciones entre los que tienen los recursos a través del territorio; es el lugar que está más cercano a las principales fuentes de riqueza en el país; es capaz de dominar el flujo de la comunicación por medio de un lenguaje codificado y un conjunto de instituciones para la consulta y la representación. ${ }^{28}$

\section{LA CRISIS DE LA NOCIÓN DE FRONTERA Y EL ESTALLIDO REVOLUCIONARIO}

Desde los inicios de la vida independiente, los estados y las municipalidades habían resuelto en lo posible las épocas de penurias con la venta de terrenos a particulares, tal como lo vimos en el Norte, pero a partir de la constitución de 1857, la venta de terrenos -y por tanto, la posibilidad de obtener recursos con este medio- se convirtió en materia federal. En Chihuahua, las primeras concentraciones de la tierra por parte de las familias Terrazas y Zuloaga sucedieron en estas primeras fechas; posteriormente, con la llegada de los ferrocarriles, comenzó una segunda época en la que, en un primer momento grandes extensiones fueron deslindadas o denunciadas por funcionarios o amigos de estos; en un segundo, fueron vendidas a las compañías extranjeras para explotación ganadera, silvícola o para colonizar la zona. Para la élite política, este fue el mejor de todos los negocios, lo que algunos llamaron "la venta de la patria".

Así podemos observar que en lo de la venta de la patria, hay una competencia entre la administración central representada por Porfirio Díaz y el poder local (fronterizo), representado por los Terrazas-Creel, ambos tienen intereses comunes, como mantener la paz y sojuzgar a la población local, pero compiten en cuanto a los beneficios derivados de la inversión extranjera.

Finalmente, el 1. de julio de 1905 Díaz emitió el decreto presidencial que abolía la Zona Libre, donde argumentaba que la llegada de los ferrocarriles a la frontera, la eliminación de las alcabalas habían terminado con los propósitos originales para es-

28 Rokkan, 1982, 5. 
tablecerla y que ahora, los rancheros y ganaderos de la zona eran quienes habían pedido su desaparición para permitir el establecimiento de industrias en la zona, pero era evidente que la mayor presión había venido de los habitantes del lado norteamericano a través del Departamento de Estado aprovechando la necesidad mexicana de apoyo económico para su tránsito del patrón plata al patrón oro y que los cacicazgos norteños habían perdido mucho de su poder político como resultado del centralismo, como fue el caso de Nuevo León-Tamaulipas bajo el gobierno centralista del general Bernardo Reyes o el de Chihuahua ya con Enrique Creel como gobernante.

El 5 de mayo de 1906, a nombre del club liberal Humanidad, uno de los trabajadores más educados, profesor normalista en su natal Nayarit, periodista en Mazatlán y posteriormente empleado en la mina sonorense, Esteban Baca Calderón, pronunció un emotivo discurso sobre los problemas de los trabajadores mexicanos en el que señaló que:

Enseñadle al capitalista que no sois bestias de carga; a ese capitalista que en todo y para todo nos ha postergado con su legión de hombres blondos y de ojos azules ¡Qué vergüenza! Estáis en vuestro propio suelo y los beneficios que produce a vosotros debieran corresponder en primer lugar...29

A fines de mayo de 1906, la compañía anunció que elevaría los salarios solamente a los trabajadores norteamericanos, esto debido a la devaluación de 1905 con la nueva paridad del dólar, y el 1. ${ }^{\circ}$ de junio estalló la huelga entre los mexicanos. El pliego petitorio mexicano demandaba un salario base de cinco pesos, reducción de horas de trabajo de nueve a ocho, límite de 25 por ciento de trabajadores norteamericanos, promociones a los mexicanos y otras demandas.

Como ha señalado Claudio Lomnitz, esa frontera que debió ser un umbral mágico por donde se pasaba, o se debía pasar, "de un mundo a otro: no solo de una lengua a otra, o de una moneda a

29 González, 1957, 13. 
otra, sino de un mundo de relaciones a otro, de un pueblo a otro, y aun de un tiempo a otro". Al permitirse acciones como las de $\mathrm{Ca}$ nanea, la frontera se recorría al sur imponiendo las condiciones del anglo dominante, en lo que parecía ser una dominación no solamente económica, sino racial y cultural. ${ }^{30}$

Mientras eso sucedía en Cananea, es decir del lado mexicano, en el norteamericano los hermanos Flores Magón inciaban el Partido Liberal Mexicano y difundían sus ideas libertarias en el periódico Regeneración. La frontera servía como escudo y era posible desde ahí la lucha antiporfirista sobre todo entre los emigrados mexicanos que trabajaban en las minas y ranchos. Sin la frontera no hubiera sido posible luchar contra el centro.

La lucha de los hermanos Flores Magón fue significativa sobre todo por el apoyo de los migrantes mexicanos, y la zona de combate fue nuevamente la de la línea del río Bravo y las aduanas establecidas en su margen mexicano. El reclamo fue el mismo desde Cananea hasta el final: la línea separaba no solo a dos países, sino a dos razas, y en cierto modo defendía a una de la otra.

Con las inversiones extranjeras y la cesión de terrenos para haciendas y minas propiedad de extranjeros en México, sobre todo en la región fronteriza, la noción de frontera sufrió una enorme crisis, se desdibujaba y ya no servía como protectora de los intereses e identidad nacionales. ${ }^{31}$ El gobierno central era una madrastra para los nacionales y una madre cariñosa y atenta para los extranjeros. Los fronterizos se sintieron amenazados, desprotegidos en lo más íntimo y se unieron a la Revolución mexicana.

\section{CONCLUSIONES}

Aunque el significado de la noción de frontera ha variado a lo largo de la historia, mantiene su referencia original de "frente" y solo puede ser comprendida en su relación con su otra palabra mágica: centro. Las fronteras mexicanas fueron atendidas en términos de que generaban ingresos al centro, al gobierno federal y en ese sentido las aduanas con sus imponentes edificios marca-

30 Lomnitz, 2010, passim.

31 Anderson, 1996, 20; Baudet, 2012, 39. 
ron el dominio del poder central sobre las zonas fronterizas, pero estas zonas no solo son delimitadoras de un espacio geográfico en términos de soberanía y poder, también son útiles cuando es necesario transgredir la ley, desafiar al Estado, generan indentidad y retos permanentes. Al menos esa es la experiencia mexicana.

\section{BIBLIOGRAFÍA}

Alonso, Ana María (1995). Thread of blood. Colonialismo, revolution and gender on Mexico's Northern frontier. Tucson University of Arizona Press, 303 pp. Anderson, Malcolm (1996). Frontiers. Territory and state formation in the modern world. Polity press, $260 \mathrm{pp}$.

Baudet, Thierry (2012). Significance of Borders: Why Representative Government and the Rule of Law Require Nation States. Leiden, NLD: Martinus Nijhoff Publishers.

Bazant, Jean (1995). Historia de la deuda exterior de México 1823-1946. MéxiCo, El Colegio de México, 282 pp.

Cerutti Mario y Miguel González Quiroga (1990): “Guerra y comercio en torno al Río Bravo (1855-1867). Línea fronteriza, espacio económico común”. Historia Mexicana, Vol. 40, Núm. 2 (octubre-diciembre).

Comision Pesquisidora de la Frontera Norte al Ejecutivo de la Unión (1873). Informe, $40 \mathrm{pp}$.

González Ramírez, Manuel (1957). Fuentes para la historia de la Revolución mexicana. La huelga de Cananea. México, FCE, 300 pp.

Lomnitz, Claudio (2010). "Por mi espíritu hablara el nacionalismo revolucionario (Arqueología de la unidad nacional)” Nexos, núm. 386, febrero.

Macedo, Pablo (1905). La evolución mercantil, comunicaciones y obras públicas. La Hacienda Pública. Tres monografías que dan idea de una parte de la evolución económica de México. México unAm-Facultad de economía, 1989, 623 pp. (Colección Clásicos de la Economía Mexicana).

Meza, Robinzon (2009). "Visión de la frontera norte de Nueva España por Nicolas de Lafora (1766-1768)”. Presente y pasado. Revista de Historia. Año 13. Núm. 27. enero-junio, pp. 11-30.

Mora Torres, Juan (2001). The making of the Mexican border. Texas University Press, $182 \mathrm{pp}$. 
Nuño, Aurelio. Building a National State "without" Taxation: The Political Consequences of the Fiscal Evolution in Mexico after the Armed Revolution, 1920-1930. Thesis, St. Anthony's College, 2008.

Osorio, Rubén (1995). Tomóchic en llamas. Prólogo de Friedrich Katz. México: Conaculta, $392 \mathrm{pp}$.

Rajchenberg, Enrique y Catherine Héau-Lambert (2005). "El septentrión mexicano entre el destino manifiesto y el imaginario territorial". Journal of Iberian and Latin American Studies, 11: 1, julio.

Rokkan, Stein y Derek W. Urwin (1982). The politics of territorial identity. Studies in european regionalism. Sage, $438 \mathrm{pp}$.

Sierra, Justo (1992). Obras Completas. Tomo XII, México, UnAM, 540 pp.

Young, Elliot (1996). "Remembering Catarino Garza's 1891 Revolution: an aborted border insurrection", Mexican studies/estudios mexicanos, Vol. 12, Núm. 2, pp. 231-272. 